\title{
Uma Análise das Ocorrências de Fogo e Incêndios Florestais no Parque Nacional da Chapada Diamantina entre 2015 e 2020
}

\author{
Jaevillen F. Oliveira ${ }^{1}$, Juliana A. Pinto ${ }^{1}$, Daniel A. Costa ${ }^{1}$, \\ Adlla Katarine A. C. Passos ${ }^{1}$, Wanderson B. Silva ${ }^{1}$ \\ ${ }^{1}$ Universidade Estadual de Feira de Santana (UEFS) \\ Feira de Santana - BA - Brasil \\ \{jaevillenoliveira, aragaopintojuli\}@gmail.com, \\ \{dancostafsa, adllakatarine\}@hotmail.com, wbsilva@ecomp.uefs.br
}

\begin{abstract}
Forest fires are considered environmental catastrophes and can be provoked by human actions or natural causes. The region of the National Park of Chapada Diamantina, in the Brazilian state of Bahia, is among the National Conservation Units that register large quantities of fire spots. To address this problem, the study about this region and a surrounding area of 10 Kilometers from the Park aims to identify possible relations between atmospheric processes and the number of fire occurrences. To that end, a period of five years (2015 2020) was considered, and data from INPE and INMET, about the fire ocurrences and meteorological information, respectively, were gathered.
\end{abstract}

Resumo. Incêndios florestais são considerados catástrofes ambientais e podem ser provocados por ações humanas ou por fatores naturais. A região do Parque Nacional da Chapada Diamantina (Chapada Diamantina - Bahia) está entre as Unidades de Conservação Federais que registram grandes números de focos de incêndios. O estudo desta região, e de uma área circundante de $10 \mathrm{~km}$ do parque, tem como objetivo identificar possíveis relações entre processos atmosféricos e a quantidade de ocorrências de focos de fogo. Para isso, foi utilizada uma série temporal de 6 anos (2015 - 2020) e coletados dados disponibilizados pelo INPE e INMET, contendo registros de ocorrências de focos de fogo e dados meteorológicos respectivamente.

\section{Introdução}

Incêndios florestais são a propagação descontrolada de fogo em áreas de floresta, e dentre as diversas causas, eles podem ser ocasionados por ações humanas. Esses fenômenos podem ser provocados por fogueiras mal apagadas, acidentes com cabos de energia ou, o mais crítico de todos, o uso de queimadas para a expansão de áreas rurais, as quais os agricultores preparam o terreno para nova plantação ou até para criação de pastos. Apesar de permitidas, seu uso exige certos cuidados e só podem ser realizadas nos períodos estabelecidos pelas autoridades. Essas normas, no entanto, nem sempre são respeitadas, o que pode resultar em incêndios massivos.

Este tipo de incêndio repercute prejuízos ambientais, sendo mais crítico nas áreas de conservação de espécies de grande importância científica, ecológica e/ou em risco de extinção; o solo é prejudicado, pois fica desprotegido durante períodos de chuva, resultando em arrastamento da terra, a perda de nutrientes e a contaminação de linhas de água 
próximas; e a poluição do ar, por causa da liberação de grandes quantidades de $\mathrm{CO}_{2}$ [Filipe and Serralha 2015]. Além dos prejuízos ambientais, a fumaça e o risco da própria queimada atingindo as áreas de habitação próxima resultam em impactos sociais e econômicos. [Miranda et al. 1996].

No cenário brasileiro, a região do Parque Nacional da Chapada Diamantina (PNCD), localizado na Chapada Diamantina no estado da Bahia, é um lugar de grande importância e diversidade ecológica e ambiental em seu território. Possuindo 152.000 hectares, abrange três biomas brasileiros: Mata Atlântica, Cerrado e Caatinga. Está inserido nas Reservas da Biosfera (RB) da Caatinga e da Mata Atlântica e abrange seis municípios: Andaraí, Lençóis, Mucugê, Palmeiras, Ibicoara e Itaetê. Mesmo sendo uma zona protegida, de acordo com o IBAMA, é a Unidade de Conservação (UC) Federal que registra o maior número de focos de incêndio por temporada, apesar de não serem os de maiores extensões [Mesquita et al. 2011].

Esse grande número de ocorrências de fogo em uma região tão importante biologicamente gera bastante preocupação, e por esse motivo, se utilizando de dados extraídos de plataformas oficiais, foi realizado um estudo com objetivo de identificar possíveis relações entre processos atmosféricos e a quantidade de ocorrências de focos de fogo na região do PNCD.

\section{Trabalhos Relacionados}

Incêndios Florestais são eventos que incitam grande importância social pois afetam o meio ambiente e consequentemente a sociedade. Assim muitos estudos foram conduzidos ao longo dos anos, para as mais variadas regiões e biodiversidades, a fim de que se entenda esse fenômeno e consiga certo controle sobre o mesmo.

Um desses estudos foi feito por [Giacomin 2014] para regiões de plantio florestal entre o Norte do Espírito Santo e Sul da Bahia. No estudo o autor observou um conjunto de dados contendo as ocorrências de incêndio e as variáveis meteorológicas correspondentes no período de 2008 a 2012. Essa observação permitiu se distinguir padrões nas ocorrência de fogo da região: se identificou variáveis climáticas com relação forte com as ocorrências, períodos do ano e regiões em que eram mais frequentes.

Em um outro estudo [Mesquita et al. 2011] os autores utilizam imagens de satélite para analisar o histórico do fogo no PNCD entre os anos de 1973 e 2010 . Neste trabalho são analisadas as áreas atingidas pelo fogo em cada ano, o que possibilita conclusões acerca de quais regiões do Parque são mais suscetíveis a incêndios. Também são relacionados fenômenos meteorológicos como o El Niño, e fenômenos sociais como aspectos relacionados à criação de gado na região. No entanto, neste trabalho apenas são buscadas as causas do fogo para momentos extraordinários que se deram neste período e que são conhecidos historicamente. Uma análise relacionada aos eventos climáticos rotineiros da região não é feita nesse escopo.

Em um terceiro trabalho [Rodrigues et al. 2011] faz uma análise das ocorrências de fogo no PNCD e na sua zona de amortecimento (10Km dos territórios circundantes do Parque) nos anos de 2004 a 2009. Em sua análise os autores apontam a periodicidade do fogo (em quais épocas são mais frequentes), os locais e as causas, sendo que parte das ocorrências são originadas por atividades humanas. Ou autores não se aprofundam por- 
tanto nos aspectos meteorológicos que incitam a ocorrência do fogo, quando por causas naturais, ou que a agravam quando provocada por ações humanas.

\section{Metodologia}

Para a realização do estudo, foram coletados dados disponibilizados pelo Instituto Nacional de Pesquisas Espaciais (INPE) ${ }^{1}$ e pelo Instituto Nacional de Meteorologia (INMET) 2. As informações do INPE foram obtidas através do Banco de Dados de Queimadas, contendo os registros de cada foco de fogo detectado, sua data/hora, localização e o risco de fogo calculado pelo INPE para o período em que o foco foi detectado. Os dados do INMET continham a insolação e precipitação total, temperatura média compensada e umidade relativa do ar. O estudo é referente aos anos de 2015 à 2020 e abrange os seis municípios do PNCD, além de quatro municípios vizinhos: Boninal, Iraquara, Nova Redenção e Iramaia.

Na Figura 1 estão demarcados em verde os limites da área envolvida no estudo e em azul os limites das cidades, que envolvem o Parque e das que estão próximas nos arredores dele. A marcação verde mais interna determina o limite geográfico do PNCD e a marcação verde mais externa abrange uma área circundante (faixa de 10km) do Parque. Os quatro municípios vizinhos citados anteriormente possuem pequenas proporções de território na fronteira da faixa de $10 \mathrm{Km}$ do $\mathrm{PNCD}$, no entanto não estão dentro do Parque.

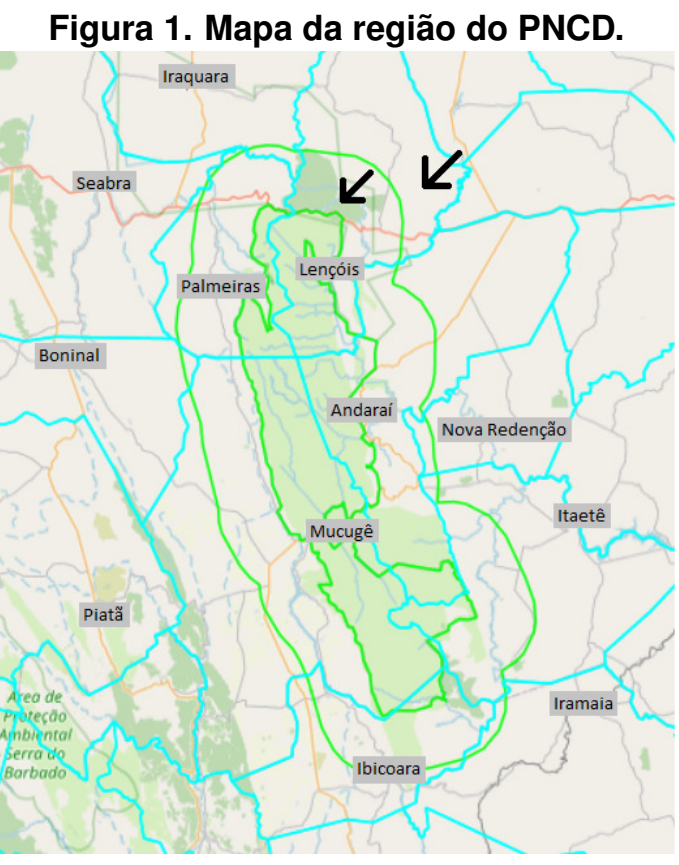

Quanto aos dados coletados, o INPE, através do uso de satélites com sensores ópticos, fornece dados referentes a cada um dos municípios citados individualmente. Já o INMET, com sua coleta por meio de estações meteorológicas convencionais e automáticas, concede dados das cidades de Andaraí, Iraquara, Itaeté, Lençóis, Nova Redenção e

\footnotetext{
${ }^{1}$ https://queimadas.dgi.inpe.br/queimadas/portal

${ }^{2}$ https://bdmep.inmet.gov.br/
} 
Palmeiras através da estação meteorológica localizada em Lençóis; das cidades de Boninal, Ibicoara, Iraquara e Mucugê por meio da estação meteorológica localizada em Piatã; e da cidade de Iramaia pela estação meteorológica localizada em Itiruçu.

Os dados da estação meteorológica convencional de Lençóis (que requer a presença diária de uma pessoa para coletar os dados medidos) foi preferível por haver mais informações consideradas relevantes para a análise proposta. Já as estações de Piatã e Itiruçu fornecem dados apenas de estações automáticas (em que a coleta de dados é totalmente automatizada) e, nesse caso, exceto os dados de insolação não são utilizados.

Os dados foram baixados em arquivos csv, organizados por mês/ano e manipulados através da linguagem de programação Python na versão 3.7, utilizando a IDE Spyder 1. A análise dos registros de ocorrências de foco de fogo foram organizados por meio de tabelas e gráficos, mostrando a relação de ocorrências por mês/ano, por estações do ano e por município. Os dados meteorológicos, foram extraídos de duas formas, os dados da estação de Lençóis foram extraídos separados por mês, onde é feita a contagem mensal dos dados, contudo nas estações de Piatã e Itiruçu os dados foram coletados por dia e feito uma média entre eles com a finalidade de se analisar os todos os dados de forma mensal. Essas informações meteorológicas foram organizadas e comparadas com a quantidades de focos nos mesmos períodos de tempo.

Nas variáveis de temperatura média, precipitação total em Itiruçu e Piatã e umidade relativa do ar em Itiruçu foram detectados valores nulos. A partir disso foi realizado o tratamento e considerando a pouca perda de informações desses valores eles foram desconsiderados, ou seja, seu valor foi considerado zero.

\section{Resultados e Discussões}

Nesta seção serão apresentados os resultados obtidos a partir da análise feita sobre os dados coletados. Na seção 4.1 será mostrado a distribuição dos focos durante os meses/anos do período; na seção 4.2 será mostrada essa distribuição pelas estações do ano; 4.3 mostra a distribuição por municípios e 4.4 mostra as relações entre os focos e as condições meteorológicas.

\subsection{Distribuição temporal das ocorrências}

Para se entender a distribuição temporal dos focos de fogo durante o período explorado (2015 - 2020) foram analisadas a quantidade de focos por mês de cada ano do período e a frequência relativa (FR) em que ocorreram esses focos ao longo dos meses no período total. Essas informações podem ser observadas na Tabela 1.

Com um total de 3707 focos, o ano de 2015 aconteceram mais incidências de focos de fogo, 5 vezes mais do que 2018, sendo este o segundo ano com mais focos. Essa discrepância se acentua ainda mais pelo fato de que as ocorrências registradas em 2015 se concentram principalmente nos meses de novembro e dezembro, que juntos somam mais de 3000 focos, enquanto que nos outros anos esses dois meses registraram uma pequena quantidade de ocorrências.

Esse aumento no final de 2015, segundo matérias publicadas por [G1/Globo 2015] e [Cazarré 2015], foi causado por eventos de ação humana que culminaram em grandes

\footnotetext{
${ }^{1}$ https://www.spyder-ide.org/
} 
Tabela 1. Ocorrências por mês/ano.

\begin{tabular}{lcccccccc}
\hline Mês & $\mathbf{2 0 1 5}$ & $\mathbf{2 0 1 6}$ & $\mathbf{2 0 1 7}$ & $\mathbf{2 0 1 8}$ & $\mathbf{2 0 1 9}$ & $\mathbf{2 0 2 0}$ & Ocorrências & FR(\%) \\
\hline Janeiro & 157 & 133 & 73 & 4 & 10 & 6 & 383 & 6,76 \\
Fevereiro & 7 & 7 & 8 & 12 & 17 & 8 & 59 & 1,04 \\
Março & 9 & 19 & 34 & 68 & 44 & 0 & 174 & 3,07 \\
Abril & 4 & 26 & 9 & 1 & 13 & 0 & 53 & 0,94 \\
Maio & 3 & 35 & 4 & 5 & 6 & 57 & 110 & 1,94 \\
Junho & 1 & 28 & 13 & 4 & 59 & 3 & 108 & 1,91 \\
Julho & 1 & 15 & 10 & 10 & 9 & 4 & 49 & 0,87 \\
Agosto & 11 & 27 & 11 & 25 & 10 & 2 & 86 & 1,52 \\
Setembro & 346 & 89 & 8 & 48 & 16 & 35 & 542 & 9,57 \\
Outubro & 153 & 35 & 142 & 505 & 74 & 19 & 928 & 16,38 \\
Novembro & 1607 & 7 & 2 & 22 & 46 & 9 & 1693 & 29,89 \\
Dezembro & 1408 & 6 & 6 & 7 & 38 & 14 & 1479 & 26,11 \\
Total & 3707 & 427 & 320 & 711 & 342 & 157 & 5664 & 100,0 \\
\hline
\end{tabular}

incêndios, os quais, segundo [G1/Globo 2015], só no mês de novembro queimaram cerca de 8000 hectares de vegetação do parque, acarretando consequências à fauna, à flora e às nascentes que compõem a região. Um outro fator contribuinte para a expansão do fogo foi a seca que segundo [Marengo et al. 2016] já vinha assolando o Nordeste brasileiro desde 2012, e em 2015 foi agravada pelo fenômeno do El Niño (este fenômeno, segundo [Costa 2012], causa alterações no tempo e no clima em regiões de todo o planeta e, no Nordeste brasileiro, costuma causar longos períodos de seca).

Figura 2. Frequência relativa de ocorrências por ano.

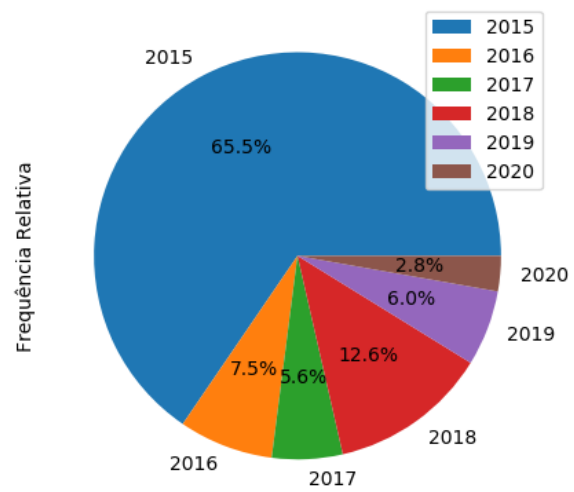

Pelo período total analisado, os meses com menor incidência foram aqueles entre fevereiro e agosto que, com exceção de março, contabilizaram menos de $3 \%$ dos focos (cada). Já os meses com maior incidência foram setembro e outubro, que ao longo de todo o período registraram quantidades maiores de focos do que os outros meses, e novembro e dezembro que, apesar de registrarem menos incidência nos anos de 2016 a 2020, acumularam maior parte dos focos de 2015. A frequência relativa desses focos por ano pode ser analisada na Figura 2.

\subsection{Distribuição das ocorrências por estações do ano}

Analisar as ocorrências por estações do ano permite-se fazer associações entre as incidências e as características meteorológicas predominantes de cada estação. Pela Figura 3 
observa-se que a estação mais suscetível à focos de fogo na região do Parque é a primavera. Segundo [CPTEC/INPE 2020] a primavera é caracterizada como a estação seca em grande parte da Região Nordeste, o que explica o aumento dos focos.

Figura 3. Frequência relativa de ocorrências por estações do ano.

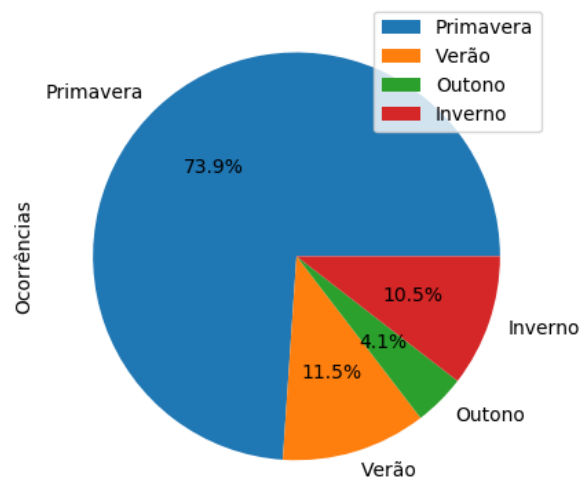

Por outro lado, a estação em que foram registrados menos focos de fogo foi o outono, que ocorre de março à maio, e é a estação de transição entre o verão e o inverno. Essa transição de uma estação quente e chuvosa para uma mais fria resulta em um período de temperaturas amenas e redução do volume de chuvas. Essas características indicam que a probabilidade de incêndios naturais não é tão acentuada, mas caso ocorram incêndios por outras causas, o outono não é a estação mais favorável ao combate do fogo, justamente pelo menor volume de chuvas.

O verão é uma estação quente e com ocorrências de chuvas repentinas, fortes e curtas geralmente acompanhadas de trovoadas. A ocorrência de fogo nesse período (dezembro a fevereiro) foi de $11,5 \%$. No inverno houveram 10,5\% do total das ocorrências. A estação é caracterizada por temperaturas mais baixas, frentes frias, inversões térmicas (causando nevoeiros) geralmente pela manhã, enquanto que às tardes a umidade relativa fica mais baixa, provocando ar seco. O inverno acontece no período de junho a agosto.

\subsection{Distribuição das ocorrências por região}

Analisando a quantidade de ocorrências em cada município integrante do parque (Tabela 2) detecta-se maior concentração de focos nas regiões de Mucugê $(40,66 \%)$, Lençóis $(20,99 \%)$, Palmeiras $(12,41 \%)$ e Ibicoara $(11,30 \%)$. Os municípios de Itaetê e Andaraí juntos cobrem as áreas mais à nordeste e sudeste do Parque, e somam mais 13,47\% dos focos detectados. Essa concentração é proporcional à porcentagem territorial que cada município abrange dentro do Parque, portanto percebe-se que os focos estão bem distribuídos ao longo da região. Os demais municípios (Iraquara, Iramaia, Nova Redenção, e Boninal) não ocupam território do Parque, apenas pequenos territórios nos arredores. Nesses foram detectados poucos focos (66 no total).

\subsection{Quantidade de ocorrências $x$ fatores meteorológicos}

No que diz respeito à eventos ambientais, as características do meio tem impacto direto nas consequências finais. No caso de incêndios florestais, o estado da vegetação e a condição climática podem determinar se uma fogueira mal apagada vai se extinguir sem causalidades ou vai ser o início de um incêndio de maiores proporções. Por esse motivo se fez uma análise das condições climatológicas durante as ocorrências de fogo constatadas. 
Tabela 2. Ocorrências por município

\begin{tabular}{lcc}
\hline Município & Ocorrências & Frequência Relativa (\%) \\
\hline Palmeiras & 703 & 12,41 \\
Lençóis & 1189 & 20,99 \\
Mucugê & 2303 & 40,66 \\
Ibicoara & 640 & 11,30 \\
Andaraí & 365 & 6,44 \\
Boninal & 3 & 0,05 \\
Iraquara & 35 & 0,62 \\
Itaete & 398 & 7,03 \\
Iramaia & 20 & 0,35 \\
Nova Redenção & 8 & 0,14 \\
Total & 5664 & 100,0 \\
\hline
\end{tabular}

\subsubsection{Quantidade de ocorrências x Umidade Relativa do ar, média mensal(\%)}

Os gráficos das Figuras 4(a) e 4(b) apontam que, durante os anos de 2015 a 2020, o período em que houve menos incidência de fogo foi o período em que a umidade do ar esteve mais alta, entre os meses de fevereiro e agosto. Nesse período a umidade esteve acima de 70\%, e chegando a mais de $80 \%$ em junho na região das estações de Lençóis e Itiruçu. Em contrapartida, os meses compreendidos entre as estações da primavera e do verão registraram mais ocorrências assim como umidade mais baixa em Lençóis e Piatã, chegando a valores abaixo de $65 \%$.

Figura 4. Ocorrências x Umidade Relativa do ar 2015 - 2020

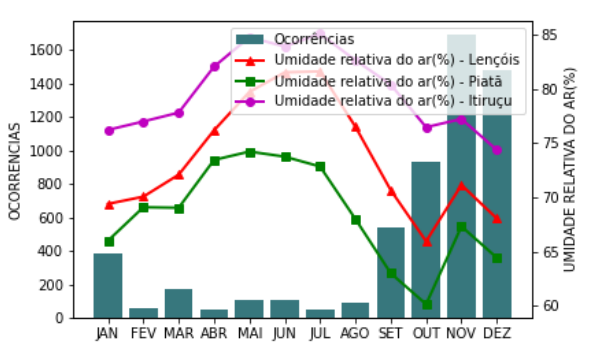

(a) Umidade por mês

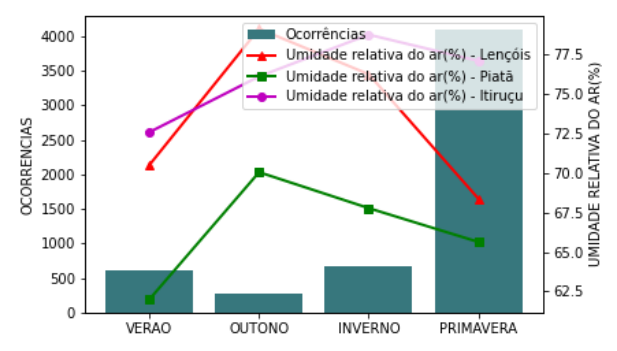

(b) Umidade por estação

\subsubsection{Quantidade de ocorrências x Insolação Total, mensal(h)}

A insolação, medida em horas, é um indicador da incidência de radiação solar no local. Segundo [Santos et al. 2009] a insolação apresenta uma relação direta proporcional com a temperatura e inversamente proporcional com a umidade. Assim, como esperado, os gráficos das Figuras 5(a) e 5(b), que analisam a relação entre insolação e quantidade de focos, mostram curvas aproximadamente opostas às das Figuras 4(a) e 4(b), relacionadas à umidade. 
Figura 5. Ocorrências x Insolação Total 2015 - 2020

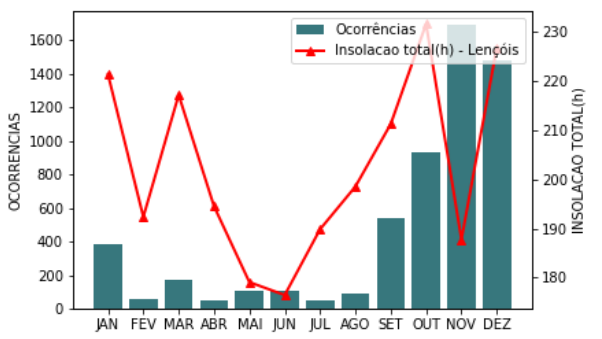

(a) Insolação por mês

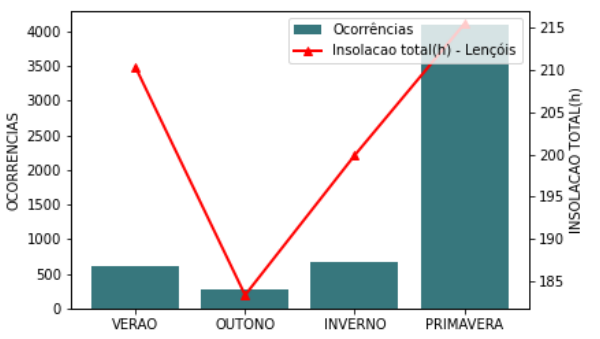

(b) Insolação por estação

Analisando o gráfico da Figura 5(a) não fica tão clara a relação entre a insolação e a quantidade de focos, pois vemos amostras, como nos meses janeiro, março e outubro, onde as incidências de focos foram baixas apesar dos altos níveis de insolação. Porém, a teoria se mostra mais evidente na prática quando vista através de períodos maiores, especificamente através das estações do ano, como mostrado no gráfico da Figura 5(b). As estações com maior número de focos são também aquelas com mais horas de exposição à radiação solar. O que também é consistente com as características de cada estação, sendo a primavera e o verão comumente conhecidas por seu clima mais seco e temperaturas mais elevadas.

\subsubsection{Quantidade de ocorrências x Precipitação Total, Mensal(mm)}

Nas Figuras 6(a) e 6(b) os períodos com maior precipitação são os que concentram a menor quantidade de focos, enquanto que os períodos com maior deficit hídrico têm maior número de casos. Isto se deve à maior quantidade de água no sistema o que inviabiliza a formação de material combustível seco.

Pela Figura 6(a), na região da estação de lençóis, o primeiro trimestre conta com níveis maiores de precipitação e poucos focos, condizendo com a descrição de [Torres 2006]. A partir de abril, no entanto, o volume de chuva começa a diminuir e, apesar dessa queda, os focos não aumentam imediatamente por causa da alta umidade registrada no mesmo período (Figura 4(a)). Porém nos últimos quatro meses, com algumas variações da precipitação a queda da umidade, a quantidade de focos aumenta. Nas estações de Piatã e Itiruçu, no entanto, os valores de precipitação registrados permanecem próximos de zero.

Figura 6. Ocorrências x Precipitação Total 2015 - 2020

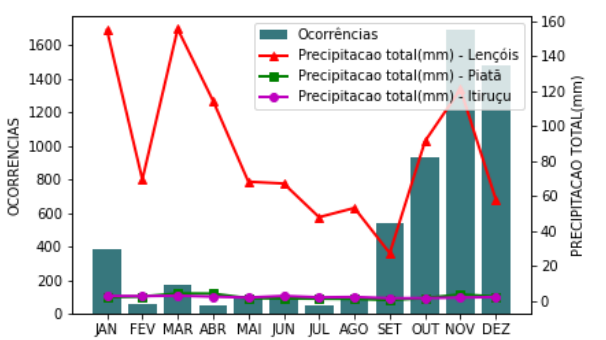

(a) Precipitação por mês

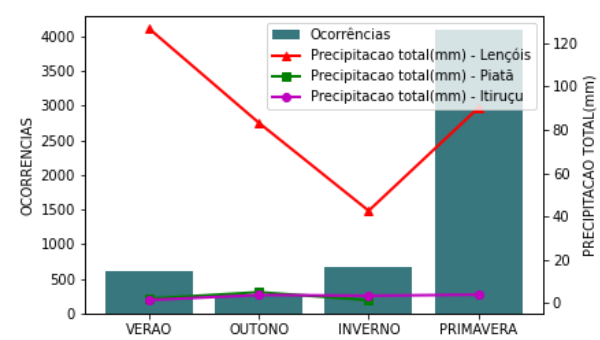

(b) Precipitação por estação 


\subsubsection{Quantidade de ocorrências x Temperatura Média Compensada, Mensal $\left({ }^{\circ} \mathrm{C}\right)$}

Segundo [Torres et al. 2010], a radiação solar tende a aumentar a temperatura ambiente, e com isso há decréscimo na umidade relativa do ar. Como a umidade relativa do ar é a relação entre a concentração de umidade contida no ar e o total que o ar comporta, os valores relativos diminuem em função do aumento da temperatura. Portanto, temperaturas altas significam umidade baixa e, consequentemente maior risco de incêndios. Isso pode ser verificado nos gráficos das Figuras 7(a) e 7(b).

Figura 7. Ocorrências x Temperatura Média Compensada 2015 - 2020

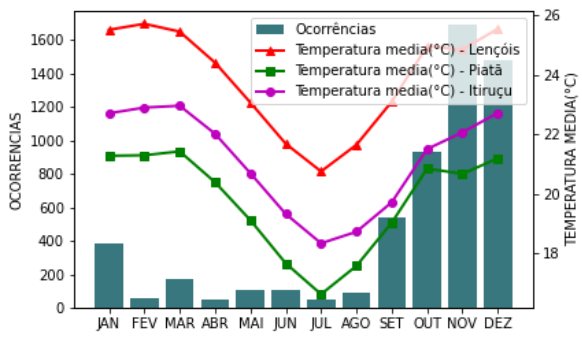

(a) Temperatura por mês

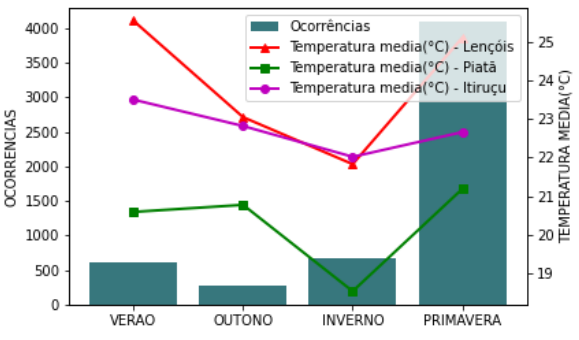

(b) Temperatura por estação

No gráfico da Figura 7(a) os meses de maio a agosto registraram temperaturas mais baixas e poucas ocorrências de focos, o que condiz com o esperado. Da mesma forma, os meses de setembro a dezembro registraram temperaturas mais elevadas e a maior quantidade de ocorrências. Já os meses de janeiro a abril registraram temperaturas altas e poucas ocorrências, porém nesse mesmo período, com exceção de janeiro, foram registrados níveis altos de precipitação na estação de Lençóis (Figura 6(a)), equilibrando o ambiente e desfavorecendo o aparecimento de focos.

\section{Conclusão}

Neste trabalho foram estudadas as ocorrências de fogo na região do PNCD durante o período de 2015 à 2020. As análises foram feitas a partir de base de dados obtidas através do INPE e do INMET. Em uma primeira análise percebeu-se que no ano de 2015 foram detectados muito mais focos de fogo do que nos demais anos (65,5\% do total). Também veio a conhecimento que esse aumento foi causado por ações humanas, as quais podem ter sido agravadas pelo fenômeno do El Niño, que intensificou uma seca já preexistente.

Também se observou que nessa região as incidências de fogo são mais frequentes durante a primavera, e que o período com menos incidência é na estação do outono. Identifica-se assim os períodos mais críticos, em que se deve direcionar recursos de combate ao fogo com mais urgência, além de deixar a população alerta para que se redobre a atenção e os cuidados.

Quanto às condições meteorológicas, foram avaliadas a umidade, insolação, precipitação e temperatura no período das ocorrências. Todas as variáveis apresentam algum tipo de relação entre si. A insolação aumenta a temperatura do meio; altas temperaturas baixam a umidade relativa do ar, deixando o ar e a vegetação mais secos, o que aumenta $o$ 
risco de incêndios. Já a precipitação torna a vegetação menos favorável ao fogo, indicando que períodos de muita chuva não apresentam muitos casos de focos de fogo.

\section{Referências}

Cazarré, M. (2015). Responsável por parque da chapada diamantina suspeita de incêndios criminosos. Disponível em: https://agenciabrasil.ebc.com.br/geral/noticia/201511/incendios-na-chapada-diamantina-sao-provocados-por-acao-humana. Acesso em: 8 Dez. 2020.

Costa, J. (2012). O fenômeno el niño e as secas no nordeste do brasil.

CPTEC/INPE (2020). Estações. Disponível em: https://clima1.cptec.inpe.br/estacoes. Acesso em: 8 Dez. 2020.

Filipe, M. and Serralha, N. (2015). Os impactos e consequências dos incêndios florestais. Disponível em: https://dica.madeira.gov.pt/index.php/outros-temas/florestas/1154-osimpactos-e-consequencias-dos-incendios-florestais. Acesso em: 21 Dez. 2020.

G1/Globo (2015). Fogo destruiu quase 8 mil hectares no parque da chapada em novembro. Disponível em: http://g1.globo.com/bahia/noticia/2015/12/fogo-destruiu-quase-8-milhectares-no-parque-da-chapada-em-novembro.html. Acesso em: 8 Dez. 2020.

Giacomin, G. (2014). Ocorrências de incêndios em povoamentos florestais no norte do espírito santo e sul da bahia. Universidade Federal do Espírito Santo.

Marengo, J., Cunha, A., and Alves, L. (2016). A seca de 2012-15 no semiárido do nordeste do brasil no contexto histórico.

Mesquita, F., Lima, N., Gonçalves, C., Berlinck, C., and Lintomen, B. (2011). Histórico dos incêndios na vegetação do parque nacional da chapada diamantina, entre 1973 e abril de 2010, com base em imagens landsat. Biodiversidade Brasileira-BioBrasil, (2):228-246.

Miranda, H., e Silva, E. R., and Miranda, A. (1996). Comportamento do fogo em queimadas de campo sujo. Impactos de queimadas em áreas de cerrado e restinga, pages $1-10$.

Rodrigues, R., Borges, E., and Franca-Rocha, W. (2011). Identificação das zonas de ocorrência de incêndios no parque nacional da chapada diamantina - ba. XV Simpósio Brasileiro de Sensoriamento Remoto - SBSR, pages 8043-8050.

Santos, D., Araujo, S. M., Araujo, K. D., Rosa, P. R., and JR, E. P. (2009). Variabilidade temporal da radiação solar e insolação no município de araguaína-to. Revista Raega, (18):35-40.

Torres, F. (2006). Relações entre fatores climáticos e ocorrências de incêndios florestais na cidade de juiz de fora (mg). Caminhos de Geografia, 7(18).

Torres, F., Ribeiro, G., Martins, S., and Lima, G. (2010). Determinação do período mais propício às ocorrências de incêndios em vegetação na área urbana de juiz de fora, mg. Revista árvore, 34(2):297-303. 